\title{
A Discussion of the Practicality of the Visual Literacy Competency Standards for Higher Education
}

\author{
Gülbin Zeren Nalinci \\ Amasya University, Turkey \\ gulbinzeren.nalinci@amasya.edu.tr
}

Mehmet Yapıc1

Amasya University, Turkey

myapici69@gmail.com

\begin{abstract}
Development and assessment of critical approaches to information technologies and multimedia practices are inevitable in our modern age, which is characterized by incessant messages conveyed through mass media and by breathtaking technological advances. Multiliteracy is required for accurate use, perception, and interpretation of communication technologies, which constantly penetration into our lives, in educational and instructional processes. The meaning of literacy changed in the $21^{\text {st }}$ century, and images, which are commonly used now, have led to visual literacy skills.

In parallel with the swift changes in the nature of information, higher education institutions have adopted various structural regulations and contemporary methods. In this way, the efficiency of the teaching-learning process is enhanced, and students are prepared for modern life. Within an educational process by which scientific and techno-cultural phenomena are reconstructed, visual literacy enables one to access images and visual materials in all areas. Therefore, individuals are required to have certain competencies so that they can objectively evaluate, subjectively criticize, and accurately reproduce, transform and use images.

Success in higher education is becoming more and more dependent on visual literacy skills. The Visual Literacy Competency Standards for Higher Education presents guidelines for educators and provides a scientific framework in which students can acquire visual literacy skills and use visual media in a critical way throughout their professional career.

The Visual Literacy Competency Standards for Higher Education was composed by the American Association of College and Research Libraries (ACRL). By means of
\end{abstract}


these standards, the members of the association identified the domains of visual literacy and specified what learning outcomes could enable students to acquire visual literacy skills. The present paper is a discussion of the extent to which the Visual Literacy Competency Standards for Higher Education can be met.

Keywords: Higher education, Visual literacy, Standards, Competency 


\section{Introduction}

Technological advances have led to communication sources, as well as visual and auditory tools, resulting in international information transfer on an unprecedented scale. The technological revolution, which, according to Zeren (2006), is especially focused on information technologies and communication, calls for other skills and competencies than basic literacy. It is only through multiliteracy one can read and interpret information and get involved in visual thinking. It is an inevitable part of our modern age, which is characterized by breathtaking technological advances, to make sense of and evaluate information technologies and multimedia practices as well as their extensions. One needs to be not only scientifically or technologically literate but also visually literate in order to accurately use and recognize communication technologies, which constantly penetrate into our lives.

Visual literacy refers to a series of visual skills that one can acquire by integrating all experiences of his/hers that are based on sight or other senses. Acquisition of visual competencies is the basis for any human learning. Once they acquire these competencies, visually literate individuals can interpret or distinguish between surrounding events, symbols, and natural or artificial images (Debes, 1969).

The definition by the International Visual Literacy Association is still valid. The association describes visual literacy as follows (Fransecky and Debes, 1972, p.7):

- Visual literacy is a series of visual competencies that one can acquire both by seeing and through other sense-related experiences.

- Visual literacy is a skill acquired to interpret the communication conducted through visual symbols (images) and to generate messages via visual symbols.

- Visual literacy is the ability to translate what is pictorial into verbal language, and vice versa. 
Visual literacy is competency in reading and understanding visual elements and the ability to think and learn through them. A review of literature in visual competency suggests that visual communication has its own codes and principles and it is a "language" different from and independent of verbal expression. The focus on having a distinct language and functionality is something that up-to-now definitions of visual literacy have in common (Zeren and Arslan, 2009).

On the other hand, the American Association of College and Research Libraries (ACRL) describes the term as follows: Visual literacy is the ability to use a series of skills required for effectively finding, interpreting, evaluating and creating images and visual media. Visual literacy enables one to understand and analyze visual materials contextually, culturally, ethically, aesthetically and intellectually as well as the technical components of generating and using images. A visually literate individual is not only a critical consumer of visual media but also someone who can make competent contributions to common information and culture (ACRL, 2011).

The use of visual materials in the learning-teaching processes is so common in the modern world that there is a need for a philosophical framework to reflect on and make sense of visual materials. Such a framework was first put forward by the American Association of College and Research Libraries (ACRL) in the form of the Visual Literacy Competency Standards for Higher Education. In March 2010, the ACRL Information Literacy Standards Committee submitted some recommendations to the Image Resources Interest Group (IRIG) for the development of visual literacy standards. The Visual Literacy Standards Task Force (VLTF) reviewed the literature, shared their results with a group of consultants- including librarians, technicians, curators and several administrators- and held meetings with different segments of society. In this way, they collected information about visual literacy standards. At the end of their studies, they formed a text on the basis of the Information Literacy Standards 
and published the rough draft in February 2011. With an interdisciplinary approach, the draft attempted to fill a significant gap in the literature. In this way, they determined the domains of visual literacy and specified what learning outcomes could enable students to acquire visual literacy skills (ACRL, 2011).

Success in higher education is becoming more and more dependent on visual literacy skills. The Visual Literacy Competency Standards for Higher Education presents guidelines for educators and provides a scientific framework in which students acquire visual literacy skills and use visual media in a critical way throughout their professional career. Furthermore, domains of standards, performance indicators and learning outcomes enable the progress displayed by students of different disciplines in visual literacy to be observed, measured, compared and discussed with a common language. The seven standards expect students (ACRL, 2011):

1) to determine the quality and scope of the visual materials they need,

2) to access images and contents of visual media effectively and efficiently,

3) to analyze and interpret images and visual media,

4) to assess images and their sources,

5) to use images and visual media effectively,

6) to design meaningful images and visual media content, and

7) to become aware of the ethical, legal, social and economic dimensions of images and visual media, and to use visual materials through an ethical approach.

\section{Method}

In this qualitative study, document analyze technique has been used . This method depends upon examining collected data and records. All kinds of written materials giving information about the subject of the research are named as documents (Yildirim and Simsek, 2013). 


\section{The Visual Literacy Competency Standards}

\section{Standard 1: To Determine the Nature and Extent of the Visual Materials Needed}

Visually literate students should be able to define and express their need for a particular image. Within the scope of an academic project, they decide how to use visual materials in accordance with the purpose of the project. The process can be planned in different ways, such as collecting proof in reference to the project, searching for the presentation of the project, conducting critical analysis, or including potential comments on the project. It is visually literate individuals who make these decisions. In this respect, they determine the contents and discourse of visual materials in reference to its target audience. Certain standards should be specified so that images can serve the purpose. The target audience should be taken into consideration while decisions are made on the subject, pictorial content, color, and resolution. The main idea and keywords should be determined to describe visual materials in an appropriate way. Visually literate students are able to define various image sources, visual materials, and types. In addition, they can come up with the type of visual design that best fits the purpose through integration, addition, or removal (ACRL, 2011).

\section{A Sample Case for Standard 1}

Imagine that a group of students take the course Effective Communication as part of their undergraduate education and choose "conflicts in domestic communication and solutions" for their end-term project. A student with the knowledge and skills specified by Standard 1 is expected to do as follows within the scope of the project:

1. to review newspapers, journals and academic publications to find images suitable for the quality and scope of the subject,

2. to link images found with the subject, justifying through images,

3. to choose and list images in accordance with the academic and affective requirements of the target audience, and to determine the length of presentation, and 
4. to associate images with a main idea that will reflect them in the most suitable way.

\section{Standard 2: To Access Images and Visual Media Effectively and Efficiently}

Visually literate students choose the most suitable sources and access systems in order to find and access needed images and visual media. For this purpose, they can determine subjectspecific and interdisciplinary image sources. In addition, they are able to express what the advantages and disadvantages of various types of image sources and access systems are. During the process of image search, they consider the rights and limitations associated with images. They can choose and use image sources that provide specialized online or in-person services (like online guides for search, image and reference librarians, curators, archivists, discipline-specific experts), as well as selecting the most appropriate image sources for the given study or project. Besides, they are involved in effective image searches and adopt a search strategy suitable for needed images and available sources. They do not neglect the fact that textual information plays a role in the process by which image content is accessed; in addition, they are able to determine the types of textual information and metadata that accompany images (such as captions or other similar illustrations, personal tags or those tags that are created by users). They can also notice that images are generally arranged in a different way than text-based information and this has an influence how one accesses images (lack of full-text search, variances in controlled words, absence of subject-specific terminology). They can figure out what keywords, synonyms or words are associated with images they need as well as linking these words with those found in image sources. By means of exploration, social mapping, engines specifically designed for visual search and browsing, they are able to make use of available images to come up with other needed images. While searching for images and their sources, they can proceed to different areas. In addition, they are able to evaluate the quality, quantity and relevancy of accessed images, and change their search strategy when necessary. They can get information about images and their 
sources. In this respect, they can access or reproduce the type of images they need by using appropriate technology and systems (like downloads, copy-paste, scanning, and cameras). When necessary, they establish first-hand contact with needed images in order to reinforce the purpose of image search (like paying visits to archives, stores, museums, galleries or libraries). They are also able to arrange images and accompanying textual information in a way that will enable them to use them again or refer to them for academic purposes (ACRL, 2011).

\section{A Sample Case for Standard 2}

Imagine that a group of students take the course Art Education as part of their undergraduate education and choose "leading movements of painting art in the $20^{\text {th }}$ century and their representatives" for their end-term project. A student with the knowledge and skills specified by Standard 2 is expected to do as follows within the scope of the project:

1. to determine those images that best fit the purpose by attempting to access images of national and international institutions and organizations,

2. to observe use rights and copyrights associated with images chosen and to take action for any necessary measures related to the purpose,

3. in this respect, to contact concerned institutions or people when necessary,

4. to determine the most appropriate images through search engines and social media,

5. to assess and classify images accessed, to choose the most appropriate ones, and to design them in accordance with the nature of the subject,

6. to make particular additions or removals on images in a faithful way, and

7. to take into account the interests and requirements of the target audience while presenting images. 


\section{Standard 3: To Analyze and Interpret Images and Visual Media}

Visually literate students can analyze the meanings of images and visual media, as well as identifying information associated with those meanings. They take a careful look at images, identify details linked with images or other physical details, and reads captions, metadata and other textual information so that they know more about images. In addition, they can decide what subjects are covered in images, determine how different images are linked with each other, and use these connected images to ensure better interpretation. They can determine whether an image requires further information, identifies questions for advanced search, and carries out extra studies when necessary.

Visually literate students can locate an image in its cultural, social and historical background. They are able to reveal cultural and historical factors in the emergence of an image (e.g. age, geography, economic conditions, political forms, and social practices) as well as attempting to identify what meanings are conveyed and what purposes are served by an image in its actual context. They try to find out what choices are made in the emergence of an image so that they can construct meaning or reinforce their interpretation (e.g. framework, composition, internal and external elements, presentation). Furthermore, they can specify the target audience for an image. They analyze images to find what they represent in social, gender, ethnic and cultural terms. They are able to trace the history of an image in reference to changes it undergoes in its audience, context and interpretation over time (ACRL, 2011).

\section{A Sample case for Standard 3}

Imagine that a group of students take the course Media Literacy as part of their undergraduate education and choose "the natures of images used in social media" for their end-term project. A student with the knowledge and skills specified by Standard 3 is expected to do as follows within the scope of the project: 
1. to determine what images are associated with the conceptual framework for social media (pictures, photographs, caricatures, videos, drawings, illustrations, animations, and so forth),

2. to determine the nature of images used in social media,

3. to determine the purpose and message (either explicit or implicit) of images used in social media,

4. to assess and interpret images used in social media by their visual values, and

5. to determine and interpret the target audience of images used in social media.

\section{Standard 4: To Assess Images and their Sources}

Visually literate students are able to assess images and their sources, their efficiency and reliability in terms of visual communication, and how efficiently they serve for a particular purpose. In addition, they can recognize the appropriateness and power of a visual message for the target audience. In this way, they can evaluate any convincing or manipulative strategies potentially used while images are generated. They are able to describe visual signs and symbols used to express visual meaning as well as determining the effect of image editing or manipulation on the meaning images convey and how reliable they are. They can identify how reliably and appropriately data are presented in graphs. By using discipline-specific standards, they can assess aesthetic and design properties of images (e.g. coloring, composition, line, form, contrast, recurrence, and style) as well as their technical properties (e.g. resolution, dimensions, definition, and file format). On the basis of such variables as color appropriateness, resolution, degree of manipulation and comparison to other reproductions, they are able to gauge the quality of a reproduced image. Moreover, they can assess textual information associated with an image in reference to precision, reliability, validity, and integrity. They can confirm textual information by observing image content, accessing various sources and carrying out research when necessary (ACRL, 2011). 


\section{A Sample Case for Standard 4}

Imagine that a group of students take the course Instructional Technologies and Material Development as part of their undergraduate education and choose "desired properties of visuals" for their end-term project. A student with the knowledge and skills specified by Standard 4 is expected to do as follows within the scope of the project:

1. to know instructional values of images and to decide what images should be used for particular target audiences,

2. to know and take into account aesthetic and design-specific considerations in image preparation,

3. to know and consider what effects particular images have on particular target audiences,

4. to assess aesthetic values of images and to obtain critical data,

5. to assess quantitatively and qualitatively textual information desired in images, and

6. to assess and validate images as well as textual information accompanying them.

\section{Standard 5: To Use Images and Visual Media Effectively}

Visually literate students can use images and visual media in an effective way for various purposes. They make strategic plans to use images and visual media in a project. While choosing an image or visual media, they take the purpose of the project into consideration. They incorporate images into the project with meticulous consideration into their meaning, aesthetic value, visual power as well as the target audience. They can use images for various purposes (e.g. illustration, proof, visual models, principal sources, and analysis-oriented projects). These purposes also include discipline-specific or interdisciplinary research, communication, and learning. They identify appropriate arrangement, presentation, communication, storage, media instruments and practices to work with and design images. They analyze images in terms of file format, dimensions and resolution as well as adapting 
images to suitable quality, layout, and display (e.g. color, contrast, and cropping). Visually literate students are able to integrate images into their academic projects through their problem-solving skills, creativity and experience. They attempt to do so in various ways. They identify and overcome problems with their visual thinking skills. They can express themselves in a better way with images. Furthermore, they can not only write clearly about images to achieve various objectives (e.g. depiction, analysis, and assessment) but also present them in an effective way by taking into consideration meaning, aesthetic standards, visual power, rhetorical content, and the target audience. They are able to communicate their opinions, explain the meaning of images and defend their stance on images so that they can be involved in critical discussion with others. They can express the meaning of an image by considering textual information when necessary (e.g. using captions, making references in a text, and including symbolic explanations or keywords). They also attempt to identify how effectively they use images and communicate visually (ACRL, 2011).

\section{A Sample case for Standard 5}

Imagine that a group of students take the course Web Design as part of their undergraduate education and choose "designing creative images" for their end-term project. A student with the knowledge and skills specified by Standard 5 is expected to do as follows within the scope of the project:

1. to apply technical information about images effectively,

2. to select the most appropriate image by taking its technical properties into account and establishing a causal link, and

3. to assess and critique the designed image in terms of appropriateness for purpose, and to offer recommendations. 


\section{Standard 6: To Design and Create Meaningful Images and Visual Media Content}

Virtually literate students are able to create and design their own images and visual media in a meaningful way, for example, for academic purposes or projects. They can explain concepts, stories and opinions by creating images and visual media (e.g. concept maps, presentations, posters, and narrative boards). They can compose precise and suitable graphical images to present data and information (e.g. tables, maps, graphs, and models). They can generate images and visual media for a particular target audience. In addition, they are able to adapt visual content to what the project is designed for. Visually literate students generate images and visual media through their creativity and design strategies. In accordance with the objectives of the project, they can make plans for visual design and style. They especially use aesthetic and design options for effective communication and improved meaning. Thanks to their creativity, they can integrate available image content with brand new visual productions. In addition, visually literate students generate images and visual media by using various tools and technologies. They select the best instruments and technologies after trying different visual production tools and technologies. They improve their skills in using a wide variety of tools and technologies that can be used for the production of images and visual media. Moreover, visually literate students are able to gauge the visual products of their own creation in reference to the objectives of the project or study. On the basis of scientific standards and traditions, they discuss visual products of their own creation with others so as to make notable contribution to research, learning, and communication. They are eager to modify images of their own creation in accordance with the results of their assessment (ACRL, 2011).

\section{A Sample Case for Standard 6}

Imagine that a group of students take the course Scientific Research Methods as part of their undergraduate education and choose "methodology and its uses in research" for their end- 
term project. A student with the knowledge and skills specified by Standard 6 is expected to do as follows within the scope of the project:

1. to determine the most appropriate image on the basis of their knowledge about image design,

2. to use images and textual information effectively and in a way that will be best understood by the target audience,

3. to ensure the fluency of the presentation with images, and to highlight the most striking and need-to-know sections,

4. to analyze images in reference to their instructional value, to discuss them with others, and to find and correct any deficiencies, and

5. to use such aesthetic elements as space, form, texture, color, ratio-proportion, balance, integrity, stress and rhythm properly and effectively on the basis of the principles of structural/formal elements.

\section{Standard 7: To Use Images and Visual Media Consciously and Ethically}

Visually literate students recognize what ethical, legal, social and economic considerations surround the way images and visual media are created, used and accessed. They know and understand most of the ethical, legal, social and economic considerations associated with images and visual media. They not only have a clear idea about what concepts and issues of intellectual property, copyright and fair use might apply to image content but also are familiar with overall license restrictions on using images appropriately. As a person who creates images, they know their own intellectual property rights, and they are able to recognize subjects linked with privacy, ethics and safety in relation to image creation, use, and share. They also conduct research on issues associated with image censorship. During the process of making progress in visual literacy, they keep themselves up to date with ethical and legal practices in the most proper way in order to compose creative images. In addition, they follow 
the policies of institutions, such as museums and schools, towards access as well as legal and ethical best practices. They observe copyright and use limitations on the way images are reproduced, changed, and converted. In addition, visually literate students can gauge visual designs in academic publications. They can recognize author rights and know how to protect or not to violate them. They can assess and interpret information and information sources included in visual materials for other researchers and scholars (ACRL, 2011).

\section{A Sample Case for Standard 7}

Imagine that a group of students take the course Visual Design and Assessment as part of their undergraduate education and choose "the significance of today's images for our lives" for their end-term project. A student with the knowledge and skills specified by Standard 7 is expected to do as follows within the scope of the project:

1. to know legal procedures for images and image use,

2. to determine the advantages and disadvantages of legal procedures for images and image use,

3. to discuss ethical considerations for images and image use,

4. to be aware of legal procedures in terms of copyright issues for images and image use,

5. to discuss ethical considerations in terms of copyright issues for images and image use, and

6. to anticipate problems that may arise from images and image use, and to make relevant recommendations.

\section{Conclusion}

An ordinary person is unconsciously under the influence of visual stimulants and messages as heavily as a downpour. Exposed to visual pollution in this respect, modern people need visual literacy so that they can stay away or protect themselves from this. A visually literate 
individual can accurately make sense of, interpret, and critique visual symptoms. In order to be able to do so, students should be made conscious and aware of visual literacy as part of an overall attitude. This is a must for modern life and modern schools.

Today's students are susceptible to images and visual materials in every single class they attend. Although they are expected to accurately make sense of, use, and form images in their academic studies, they sometimes fail to do so. Furthermore, the use of images in scientific studies requires one to have the ability to search for, interpret, analyze, and assess visual materials. This ability should be encouraged and integrated into the curriculum. In particular, certain standards for secondary education and higher education involve visual literacy as one of the key skills required for success in modern societies.

The Visual Literacy Competency Standards for Higher Education attempt to make sure that visual literacy competencies are acquired within the interdisciplinary framework of higher education. These standards provide a scientific framework in which students acquire visual literacy skills, which are required in their academic studies, and use visual media in a critical way throughout their professional career. The standards also represent observable, measureable and teachable learning outcomes for the progress students make in visual literacy. They form a common language of and instruments for discussing academic and other studies in various disciplines.

An improvement in visual literacy competency will hopefully enhance the efficiency of educational institutions, enabling visually literate students and graduates of such institutions to become more successful in both their private lives and academic careers. 


\section{References}

ACRL (2011). Association of College and Research Libraries, ACRL Visual Literacy Competency Standards for Higher Education, American Library Association (October 2011), http://www.ala.org/acrl/standards/visualliteracy (Access: 16.02.2014).

Debes, J. (1969). The loom of visual literacy, Audiovisual Instruction, 14(8), 25-27.

Fransecky, R. B. and Debes, J. L. (1972). Visual literacy: A way to learn-A way to teach.

Washington, DC: Association for Educational Communications and Technology.

Yildirim, A. Ve Simsek, H. (2013). Qualitative research methods in social sciences. (9. ed.) Ankara: Seckin.

Zeren, G. (2006). The Problem with the Identity of an Art Educator in the Information Age and Globalization, Kastamonu Education Journal, 14/2, 637-646.

Zeren, G. and R. Arslan (2009). Literacy as an Educational Process, The Turkish Journal of Social Studies, 13/2, 83-92. 